\title{
Thermodynamic and Chemical Analysis of Water-Coal Fuel Ignition and Combustion in Adiabatic Combustion Chamber
}

\author{
Viktor I. Karpenok a, Vasily I. Murko*a, \\ Vera P. Mastikhina ${ }^{a}$ and Yulia A. Loboda ${ }^{b}$ \\ ${ }^{a}$ Siberian State Industrial University \\ Novokuznetsk, Russian Federation \\ ${ }^{b}$ Tomsk State University \\ Tomsk, Russian Federation
}

Received 12.04.2021, received in revised form 11.05.2021, accepted 21.06.2021

\begin{abstract}
The article presents results of improvement of physicochemical model of coal-water fuel ignition and combustion processes, taking into account ash content and release of volatile substances of solid phase. In this case, model of ignition and combustion of two systems of atomized coal-water fuel: drops and pure coal particles is taken as a basis. As a result of the analysis, the influence of ash content of coal-water fuel on output of combustible gases and content of water vapor in furnace atmosphere was established. Based on comparison of the diffusion coefficients of gases and the calculated values of equilibrium constants of reaction in combustion zone, conclusion has been of the leading role of water vapor oxidation of carbon in vortex adiabatic furnace. Performed numerical calculations have shown that combustion process of the above inhomogeneous systems (droplets and particles) in an adiabatic furnace within a short time becomes identical. Concentrations of volatile substances, oxygen $\left(\mathrm{O}_{2}\right)$ and carbon dioxide $\left(\mathrm{CO}_{2}\right)$ in various sections of the furnace have been established.
\end{abstract}

Keywords: coal-water slury, coal-water fuel, vortex adiabatic combustion chamber, thermodynamic and chemical analysis, combustion.

(C) Siberian Federal University. All rights reserved

This work is licensed under a Creative Commons Attribution-Non Commercial 4.0 International License (CC BY-NC 4.0).

* Corresponding author E-mail address: sib_eco@kuz.ru 


\title{
Термодинамический и химический анализ
}

\section{процессов воспламенения и горения}

Водоугольного топлива

в адиабатической камере сжигания

\author{
В. И. Карпенок ${ }^{\mathrm{a}}$, В.И. Мурко ${ }^{\mathrm{a}}$, \\ В. П. Мастихина ${ }^{a}$, Ю. А. Лобода \\ ${ }^{a}$ Сибирский государственньий индустриальньий университет \\ Российская Федерация, Новокузнецьк \\ ${ }^{6}$ Томский государственный университет \\ Российская Федерация, Томск
}

\begin{abstract}
Аннотация. В статье приводятся результаты совершенствования физико-химической модели процессов воспламенения и горения водоугольного топлива с учетом зольности и выхода летучих веществ твердой фазы. При этом за основу принята модель воспламенения и горения распыленного водоугольного топлива в виде двух систем: капель и чистых угольных частиц. В результате проведенного анализа установлено влияние зольности водоугольного топлива на выход горючих газов и содержание водяного пара в атмосфере топки. На основании сравнения коэффициентов диффузии газов и рассчитанных значений констант равновесия реакции в зоне горения сделан вывод о ведущей роли реакции окисления углерода водяным паром в вихревой адиабатической топке. Выполненные численные расчеты показали, что процесс горения указанных выше неоднородных систем (капель и частиц) в адиабатической топке в течение короткого времени становится идентичным. При этом установлены концентрации летучих веществ, кислорода $\left(\mathrm{O}_{2}\right)$ и диоксида углерода $\left(\mathrm{CO}_{2}\right)$ в различных сечениях топки.
\end{abstract}

Ключевые слова: водоугольная суспензия, водоугольное топливо, вихревая адиабатическая камера сжигания, термодинамический и химический анализ, горение.

Цитирование: Карпенок, В. И. Термодинамический и химический анализ процессов воспламенения и горения водоугольного топлива в адиабатической камере сжигания / В.И. Карпенок, В. И. Мурко, В.П. Мастихина, Ю. А. Лобода // Журн. Сиб. федер. ун-та. Техника и технологии, 2021, 14(4). С. 385-398. DOI: 10.17516/1999-494X-0319

\section{Постановка проблемы}

В настоящее время наиболее эффективным и распространенным способом сжигания водоугольных суспензий (ВУС) признан вихревой способ сжигания [1-5]. Известны отдельные публикации о сжигании ВУС в псевдоожиженном (кипящем) слое [6,7], однако практического применения данная технология для котлов малой и средней мощности не получила.

Одним из основных элементов при вихревом сжигании водоугольного топлива (ВУТ) является адиабатическая камера сжигания, которая либо встраивается в топочное пространство котла (для котлов средней мощности), либо устанавливается рядом с котлом-утилизатором (для котлов малой мощности).

От правильного выбора конструкции камеры сжигания и технологических параметров горения зависит успешность применения суспензионного водоугольного топлива, поскольку оно забалластировано значительным количеством влаги и минеральных компонентов.

$$
-386-
$$


Известно также, что для эффективного зажигания и стабильного факельного горения водоугольного топлива в топочном пространстве котла, в том числе вихревой адиабатической топке, необходимо выполнение следующих условий:

- качественное распыление водоугольного топлива;

- максимально возможный подвод высокотемпературных газов к корню распыленного факела ВУТ;

- достаточное время нахождения капель распыленного топлива и угольных частиц в камере сжигания.

Организация вихревого сжигания распыленного водоугольного топлива в адиабатическом или близком к нему режиме позволяет обеспечить соблюдение указанных выше условий за счет того, что подача топлива (диспергированной водоугольной суспензии) осуществляется по касательной к условной окружности внутри топки и поток горячих топочных газов непрерывно поступает к корню факела распыла. Таким образом, в момент попадания в пространство вихревой топки диспергированные частицы (как чисто угольные, так и капли) практически мгновенно вовлекаются в вихревой горячий поток. Вихревое движение газов и распыленного топлива приводит к тому, что центробежные силы удерживают частицы и капли в пространстве топки до тех пор, пока не выгорит их горючая часть. В результате выделяющаяся минеральная часть становится легкой, смещается к оси вихря и выносится из топки с дымовыми газами.

Ранее в работах [8-10] было установлено, что существенное значение для организации стабильного горения ВУТ имеет содержание летучих веществ и зольности в частицах твердой фазы ВУТ. В научно-технической литературе этому вопросу посвящено незначительное количество работ, особенно теоретического плана. Поэтому целью данной работы явилось определение влияния основных характеристик водоугольного топлива, приготовленного на основе угольных шламов, на стабильность процессов воспламенения и горения угольных частиц и капель ВУТ с привлечением методов термодинамического и химического анализа.

\section{Основная часть}

Рассмотрим физико-химическую модель горения ВУТ с точки зрения термодинамического анализа, который позволяет оценить в комплексе влияние всех термохимических реакций, протекающих в зоне горения ВУТ. На рис. 1 представлена схема расположения различных зон при горении капли ВУТ и угольной частицы.

Попавшая в высокотемпературное пространство частица суспензии через малое время приходит в состояние, которое на рис. 1а обозначено следующим образом. Сердцевина, зона 1, представляет исходное топливо. Это суспензия, то есть смесь, совокупность воды и мелких частичек угля. Вода в этой части капли жидкая, если даже нагрета до температуры кипения. Граница между зоной 1 и зоной 2 являет собой поверхность, на которой происходит испарение воды.

Зона 2 - это расположенная поверх суспензии область высохшего топлива, то есть это частички сухого угля, между которыми находится водяной пар при температуре, превышающей температуру кипения (насыщения), то есть сухой пар. Вскоре после появления капли распыленного топлива в горячей зоне появляется разделение капли на указанные зоны. В первые

$$
-387-
$$




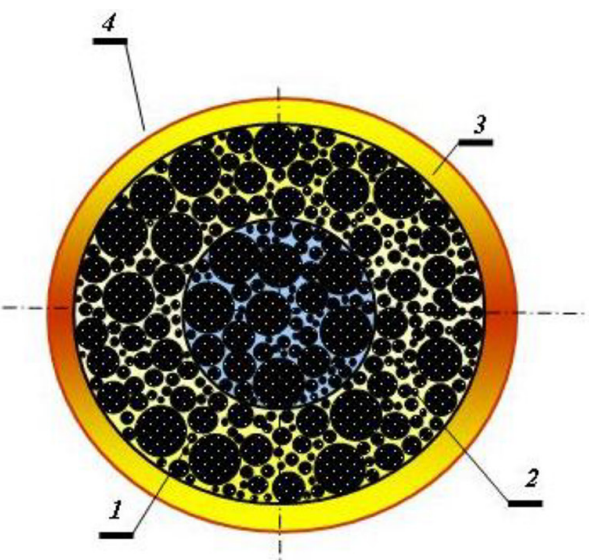

a

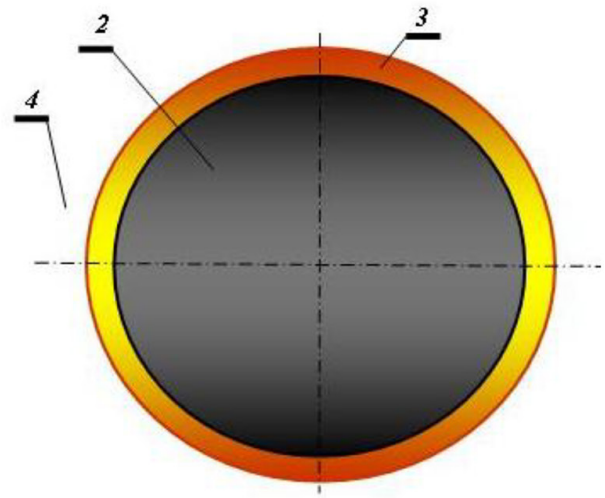

б

Рис. 1. Расположение зон в модели горения диспергированных капель ВУТ (а) и угольных частиц (б)

Fig. 1. Location of zones in the combustion model of dispersed CWF drops (a) and coal particles (б)

мгновения толщина зоны 2 крайне мала, но с течением времени радиус зоны 1 уменьшается, а толщина зоны 2 увеличивается.

Рассматривая крупные частицы (рис. 1б), которые не являются каплями, но были выделены из суспензии при распылении в форсунке, с которых потоком воздуха сорваны не только мелкие угольные частицы, но и водяная пленка, мы получим вариант, когда вся частица представляет собой зону 2. Данные частицы имеют размер 0,09-0,35 мм. В этом случае имеется нулевая концентрация водяного пара во всем объеме частицы (зона 2), а картина взаимодействия (химического и физического) поверхности частицы с зоной 3 и зоной 4 аналогична схеме на рис. 1а.

Таким образом, в случаях горения как подсохших капель ВУС (рис. 1a), так и угольных частиц (рис. 1б) мы имеем совершенно идентичные условия, а именно горение угольных частиц (пористых в случае высохших капель и сплошных в случае угольных частиц), окруженных зоной 3, за дальней границей которой находится зона 4.

Зона 3 - это зона, расположенная в непосредственной близости от поверхности капли в пространстве топки. Зона 4 - это область, удаленная от поверхности капли, то есть это пространство топки.

Рассмотрим состав газовой смеси в топочном пространстве.

Очевидно, что при повышении зольности углей количество воздуха, необходимого для сгорания 1 кг угля, уменьшается, поскольку с увеличением зольности уменьшается содержание органической массы.

В табл. 1 приведены рассчитанные количества воздуха и образующихся газов при сжигании $1 \mathrm{~m}^{3}$ суспензии, приготовленной из углей с различной зольностью при содержании твердой фазы в суспензии $52 \%$ и коэффициенте избытка воздуха $\alpha=1$. При этом количество водяного пара постоянно и составляет 647 нм³ $^{3}$.

Расчетные значения параметров, приведенные в табл. 1, соответствуют гипотетическим условиям, когда поступающие в топочное пространство материалы уже прогрелись, топли-

$$
-388-
$$


во диспергировано, вода превратилась в пар, все компоненты перемешаны между собой, но не смешаны с продуктами горения. Наряду с необходимым количеством воздуха рассчитаны концентрации кислорода и водяного пара, которые соответствуют тем же условиям, что и данные табл. 1 (рис. 2).

Как видно на рис. 2, концентрация водяного пара в атмосфере топочного пространства превысит значение половины концентрации кислорода при сжигании суспензий из угля с зольностью 20 \%. При сжигании водоугольных суспензий с более высокими значениями зольности концентрация водяного пара оказывается еще больше (при $\mathrm{A}^{\mathrm{d}}=50$ \% и выше), а концентрации кислорода и водяного пара разнятся незначительно.

После смешивания газового потока в топочном пространстве в газовой смеси существенно уменьшается концентрация кислорода. В пространстве топки он расходуется на окисление углерода, летучих компонентов угля и промежуточных продуктов горения, и несущественно

Таблица 1. Количество необходимого воздуха и образующихся газов при сжигании 1 м ${ }^{3}$ ВУТ

Table 1. Amount of required air and gases formed during combustion of $1 \mathrm{~m}^{3}$ of CWF

\begin{tabular}{|c|c|c|}
\hline Зольность, \% & $\begin{array}{c}\text { Необходимое количество } \\
\text { воздуха, } \text { нм }^{3}\end{array}$ & $\begin{array}{c}\text { Общее количество } \\
\text { газов, } \text { нм }^{3}\end{array}$ \\
\hline 0 & 7800 & 8447 \\
\hline 10 & 7020 & 7667 \\
\hline 20 & 6240 & 6887 \\
\hline 30 & 5460 & 6107 \\
\hline 40 & 4680 & 5327 \\
\hline 50 & 3900 & 4547 \\
\hline 60 & 3120 & 3767 \\
\hline 70 & 2574 & 3221 \\
\hline
\end{tabular}

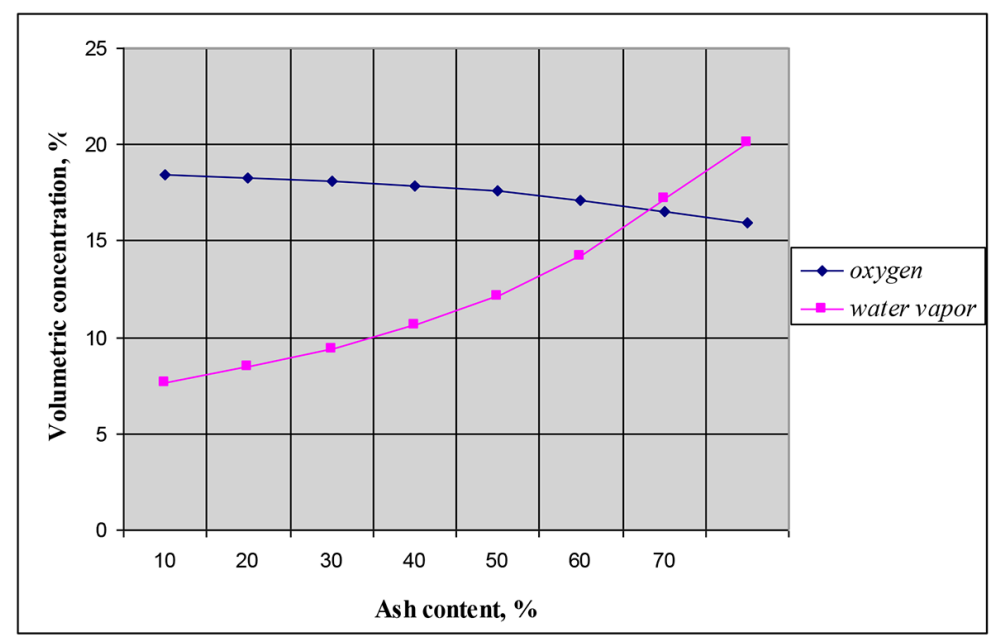

Рис. 2. Зависимость содержания кислорода и водяного пара в газовой фазе топки от зольности топлива

Fig. 2. Dependence of oxygen and water vapor content in the gas phase in furnace on ash content of the fuel

$$
-389-
$$


изменяется концентрация водяного пара. При этом концентрация водяного пара в пространстве топки достаточно высока (не менее 10 \% при сжигании суспензий из углей с зольностью $30 \%$ и выше), а для обеспечения устойчивого горения на практике потребуется повышать концентрацию кислорода, то есть повышать коэффициент избытка воздуха $\alpha$.

Если непосредственно после появления капли в высокотемпературном топочном пространстве концентрацию любого газа вблизи поверхности капли можно считать равной его концентрации в зоне 4 (на удалении от капли), то уже через малое время образуется зона 3 , обладающая особыми свойствами. Рассмотрим состав газовой фазы в зоне 3. В зоне 3 протекают различные реакции: догорают $\mathrm{H}_{2}$ и $\mathrm{CO}$, сгорают летучие, выделяющиеся из частичек угля, в этой зоне находятся самые разные вещества, как диффундирующие к поверхности капли из зоны 4, так и движущиеся от горящей поверхности в зону 4 продукты горения. Зона 3 находится в непосредственной близости от поверхности капли, и передача тепла к поверхности в пределах этой зоны осуществляется излучением и кондукцией. Из зоны 4 тепло к поверхностям капли и угольной частицы передается излучением, причем лучистый поток энергии оказывается достаточно мощным, поскольку все пространство топки заполнено горящими каплями, угольными частицами и горячими частицами золы (неизбежного компонента продуктов сгорания угля). Не нарушая общности и логики рассуждений, можно принять, что температура на поверхности горящей капли (или горящей частицы угля) быстро становится равной температуре в пространстве топки.

Как только температура поверхности частицы (или подсохшей капли) достигнет значения $250-350{ }^{\circ} \mathrm{C}$, из угля начинают выделяться летучие компоненты. Их количество существенно зависит от степени метаморфизма угля. Выделение летучих веществ из угля влияет на состав газовой фазы в зоне 3 и на интенсивность процесса горения, а вследствие этого на температурные пределы устойчивости топочного процесса при сжигании суспензионного топлива из углей различных марок.

На этой стадии существенное значение приобретают процессы массообмена, обусловленные законами диффузии.

Рассмотрим вероятность протекания различных реакций. Коэффициенты диффузии газообразных веществ согласно [11] зависят от температуры следующим образом:

$$
D(T)=D_{0} \cdot\left(\frac{T}{273}\right)^{1,5},
$$

где $D_{0}$ - коэффициент диффузии при стандартной температуре, ${ }^{2} / \mathrm{c} ; \mathrm{T}$ - температура, К.

То есть от температуры коэффициенты диффузии различных газов зависят одинаково. Из этого следует, что

$$
\frac{D_{i}(T)}{D_{j}(T)}=\left(\frac{D_{0 i}}{D_{0 j}}\right),
$$

где $D_{i}, D_{0 i}, D_{j}, D_{0 j}-$ коэффициенты диффузии отдельных газов, $\mathrm{M}^{2} / \mathrm{c}$.

Согласно (1) газы, которые выступают окислителями для углерода, имеют следующие значения коэффициентов диффузии $\mathrm{D}_{0}$ (табл. 2).

Как видно из табл. 2, величина коэффициента диффузии у водяного пара $\left(\mathrm{H}_{2} \mathrm{O}\right)$ в 1,54 раза выше, чем у кислорода $\left(\mathrm{O}_{2}\right)$ и $(\mathrm{CO})$, и в 2,85 раза выше, чем у углекислого газа $\left(\mathrm{CO}_{2}\right)$. Как сле- 
Таблица 2. Коэффициенты диффузии компонентов газовой смеси

Table 2. Diffusion coefficients of the components of the gas mixture

\begin{tabular}{|c|c|c|c|c|}
\hline Газ & $\mathrm{CO}_{2}$ & $\mathrm{CO}$ & $\mathrm{O}_{2}$ & $\mathrm{H}_{2} \mathrm{O}$ \\
\hline $\mathrm{D}_{0}, \mathrm{M}^{2} / \mathrm{c}$ & 0,097 & 0,175 & 0,18 & 0,277 \\
\hline
\end{tabular}

дует из соотношения (2), эти соотношения сохранятся при других значениях температуры. Таким образом, интенсивность диффузии водяного пара существенно превышает интенсивность диффузии кислорода и особенно углекислого газа. Это в совокупности с достаточно высокой концентрацией водяного пара в топочном пространстве обеспечивает на высохшей поверхности капли или горячей угольной частицы взаимодействие углерода практически только с водяным паром. Кислород «срабатывается на ближних подступах» к поверхности капли в реакциях окисления летучих, $\mathrm{CO}$ и $\mathrm{H}_{2}$ в зоне 3. Реакция взаимодействия углерода с $\mathrm{CO}_{2}$ крайне маловероятна из-за малого значения коэффициента диффузии $\mathrm{CO}_{2}$ и вследствие этого крайне низкой вероятности присутствия $\mathrm{CO}_{2}$ вблизи поверхностей капли и угольных частиц.

Таким образом, на границе зоны 2 и зоны 3, а также в зоне 3 протекают следующие реакции:

$$
\begin{aligned}
& 2 \mathrm{C}+\mathrm{O}_{2}=2 \mathrm{CO}+22040 \text { Дж, } \\
& \mathrm{C}+\mathrm{CO}_{2}=2 \mathrm{CO}-172470 \text { Дж, } \\
& \mathrm{C}+\mathrm{H}_{2} \mathrm{O}=\mathrm{CO}+\mathrm{H}_{2}-130560 \text { Дж, } \\
& 2 \mathrm{CO}+\mathrm{O}_{2}=2 \mathrm{CO}_{2}+565980 \text { Дж, } \\
& 2 \mathrm{H}_{2}+\mathrm{O}_{2}=2 \mathrm{H}_{2} \mathrm{O}+48216 \text { Дж. }
\end{aligned}
$$

Из числа приведенных реакций первые три являются гетерогенными и протекают на горящей поверхности частицы, а реакции (6) и (7) гомогенные и протекают в зоне 3 на некотором расстоянии (возможно, ничтожно малом, но все-таки расстоянии) от поверхности. Оценим скорости протекания реакций (3-7).

При оценке возможности протекания той или иной реакции на поверхности горящей капли следует учитывать не только гетерогенные реакции собственно окисления углерода, но и гомогенные реакции горения продуктов газификации, которые протекают в зоне 3 вблизи поверхности капли. При этом отметим, что константа равновесия реакции пропорциональна отношению концентрации продуктов реакции к концентрации исходных веществ в состоянии равновесия. Поэтому о полноте протекания химической реакции необходимо судить с учетом величины константы равновесия.

Как известно, мерой химического сродства, определяющего протекание реакции, принято считать величину изобарно-изотермического потенциала [12]:

$$
\mathrm{Z}=\mathrm{H}-\mathrm{T} \cdot \mathrm{S}
$$

который связан с константой равновесия реакции соотношением

$$
-391-
$$




$$
\mathrm{Z}=-\mathrm{R} \cdot \mathrm{T} \cdot \ln \mathrm{K}_{\mathrm{p}}
$$

где Z - изобарно-изотермический потенциал; $\mathrm{H}$ - энтальпия совокупности компонентов реакции; $\mathrm{S}$ - энтропия совокупности компонентов реакции; $\mathrm{K}_{\mathrm{p}}$ - константа равновесия реакции.

Рассчитанные величины констант равновесия реакций $(3,4,5,6,7)$ приведены в табл. 3.

При анализе данных табл. 2 и 3 видим следующее:

- коэффициент диффузии $\mathrm{CO}_{2}$ имеет самое низкое значение из числа рассматриваемых газообразных веществ;

- $\quad$ реакция (4) при любой температуре приводит к состоянию равновесия при существенно более низких концентрациях продуктов, чем любая другая реакция из числа рассматриваемых;

- равновесные концентрации продуктов окисления $\mathrm{CO}$ и $\mathrm{H}_{2}$, представляющие собой $\mathrm{CO}_{2}$ и $\mathrm{H}_{2} \mathrm{O}$ (эти реакции протекают в зоне 3), достаточно велики, что косвенно свидетельствует о высоких значениях скоростей этих реакций, а также о том, что кислород практически весь «сработается» в зоне 3, не достигнув поверхности капли. К поверхности капли будет передаваться только тепловая энергия, выделившаяся при реакциях горения $\mathrm{CO}, \mathrm{H}_{2}$ и летучих компонентов угля;

- константа равновесия реакции углерода с кислородом (реакция 6) многократно превышает значения констант реакции 7 и реакции 8 , но гомогенные реакции (9 и 10) в зоне 3 характеризуются такими значениями констант равновесия, что вероятность диффузии кислорода к поверхности частицы (или капли) попросту сводится к нулю;

- реакция (4) характеризуется самыми низкими значениями константы равновесия из трех сравниваемых гетерогенных реакций. Углекислый газ имеет не только самый низкий коэффициент диффузии из трех рассматриваемых окислителей, но и самую низкую скорость взаимодействия с углеродом во всем диапазоне рассматриваемых значений температуры.

На основании выполненного анализа можно утверждать, что на поверхности угольных частиц (и высохших капель) наиболее вероятной является реакция (8), то есть окисление углерода водяным паром. Продукты этой реакции проникают по зоне 3 к границе зоны 3 и далее в зону 4 (данная граница не может быть выделена четко) и сгорают при встрече с диффундирующим навстречу кислородом. Образующиеся $\mathrm{H}_{2} \mathrm{O}$ и $\mathrm{CO}_{2}$ характеризуются коэффициентами диффузии, различающимися почти в три раза. Поэтому водяной пар диффундирует к поверхности капли и угольных частиц существенно быстрее, чем углекислый газ. Состав газовой

Таблица 3. Константы равновесия реакций, протекающих при горении топлива

Table 3. Equilibrium constants of reactions occurring during fuel combustion

\begin{tabular}{|c|c|c|c|c|}
\hline $\begin{array}{c}\text { Температура, K } \\
\text { для реакции }\end{array}$ & 700 & 900 & 1100 & 1300 \\
\hline 3 & $1,2 \cdot 10^{24}$ & $4,0 \cdot 10^{20}$ & $1,3 \cdot 10^{18}$ & $3,3 \cdot 10^{16}$ \\
\hline 4 & $1,05 \cdot 10^{-5}$ & $8,9 \cdot 10^{-3}$ & $4,7 \cdot 10^{-1}$ & 8,0 \\
\hline 5 & $3,7 \cdot 10^{-4}$ & $8,6 \cdot 10^{-2}$ & 1,05 & 20,7 \\
\hline 6 & $1,99 \cdot 10^{11}$ & $3,13 \cdot 10^{6}$ & $2,5 \cdot 10^{3}$ & 19,07 \\
\hline 7 & $8,51 \cdot 10^{30}$ & $5,48 \cdot 10^{22}$ & $1,19 \cdot 10^{18}$ & $7,73 \cdot * 10^{13}$ \\
\hline
\end{tabular}


фазы в зоне 4 также характеризуется высокими значениями концентрации водяного пара. Эндотермичность реакции окисления углерода водяным паром не имеет решающего значения, поскольку тепловыделение от вторичных реакций (от сгорания летучих, $\mathrm{CO}$ и $\mathrm{H}_{2}$ ) происходит в крайней близости от поверхности в зоне 3.

Сделанные выводы подтверждаются результатами численного моделирования процессов горения водоугольных суспензий в адиабатической вихревой топке [13, 14]. Численные расчеты выполнены с использованием мощного программного продукта трехмерного моделирования ANSYS FLUENT, позволяющего моделировать процесс горения с учетом турбулентности, теплообмена и химических реакций. Возможности программы позволили получить расчеты полей скоростей в топочной камере, траекторий частиц, спрогнозировать температуру в различных сечениях топки.

На рис. 3 и 4 приведены сравнения изменения температуры и содержания летучих веществ в угольной частице и капле ВУТ в зависимости от длины пути частицы и капли соответственно.

Анализ представленных на рис. 3 данных показывает, что в отличие от плавного увеличения температуры угольной частицы (particle 1) при ее движении температура капли ВУТ (particle 2) после повышения до температуры испарения жидкой фазы остается постоянной на протяжении всего процесса испарения. Затем начинаются процессы горения твердой фазы капли ВУТ с выделением теплоты, и наблюдается резкое повышение температуры.

На рис. 4 видно, что содержание летучих веществ для угольной частицы (particle 1) в начале процесса остается неизменным и уменьшается только при нагреве частицы до температуры выделения летучих веществ. Для капель ВУТ (particle 2) наблюдается увеличение содержания летучих веществ за счет испарения воды. В процессе испарения температура твердой фазы капли ВУТ повышается, и содержание летучих веществ достигает аналогичного значения для твердой угольной частицы. Стабильность процесса сохраняется в течение значительно меньшего времени за счет повышения температуры твердой фазы капли ВУТ в процессе испарения воды.

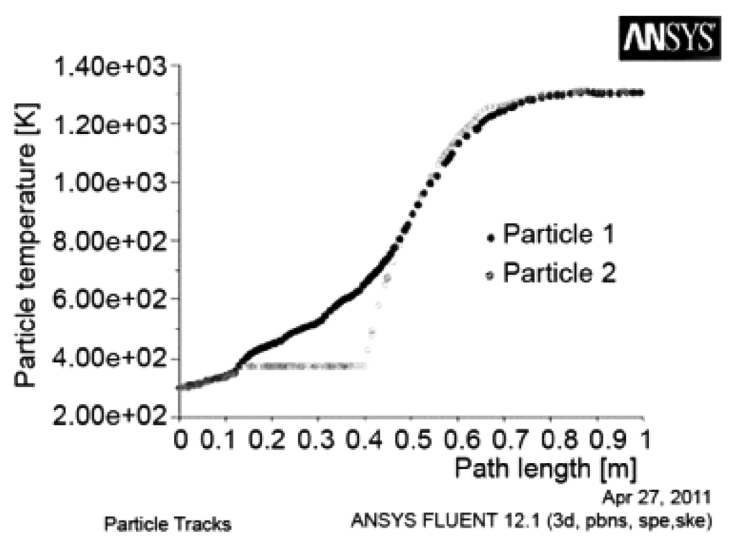

Рис. 3. Сравнение изменения температуры угольной частицы (particle 1) и капли ВУТ (particle 2) в зависимости от длины пути частицы и капли

Fig. 3. Comparison of change in temperature of a coal particle (particle 1) and a CWF drop (particle 2) depending on length of path of a particle and a drop 


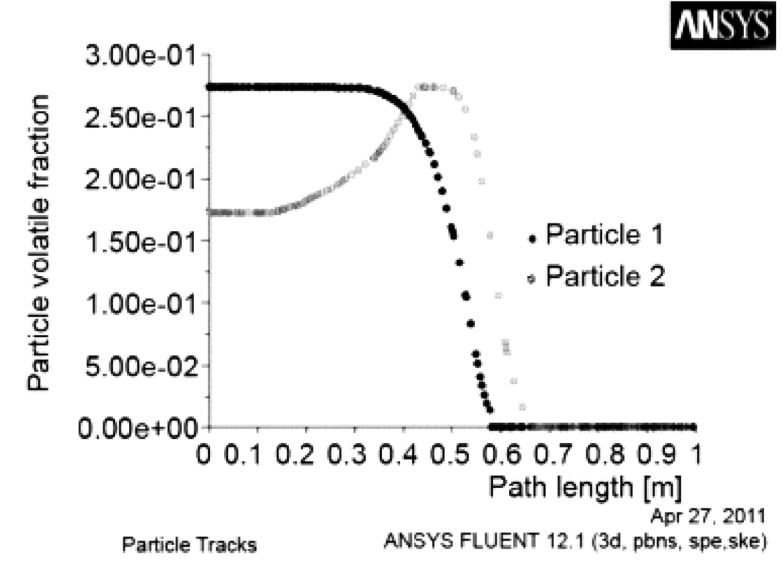

Рис. 4. Сравнение изменения содержания летучих веществ в угольной частице (particle 1) и капле ВУТ (particle 2) в зависимости от длины пути частицы и капли

Fig. 4. Comparison of changes in content of volatiles in a coal particle (particle 1) and a CWF droplet (particle 2), depending on path length of a particle and a droplet
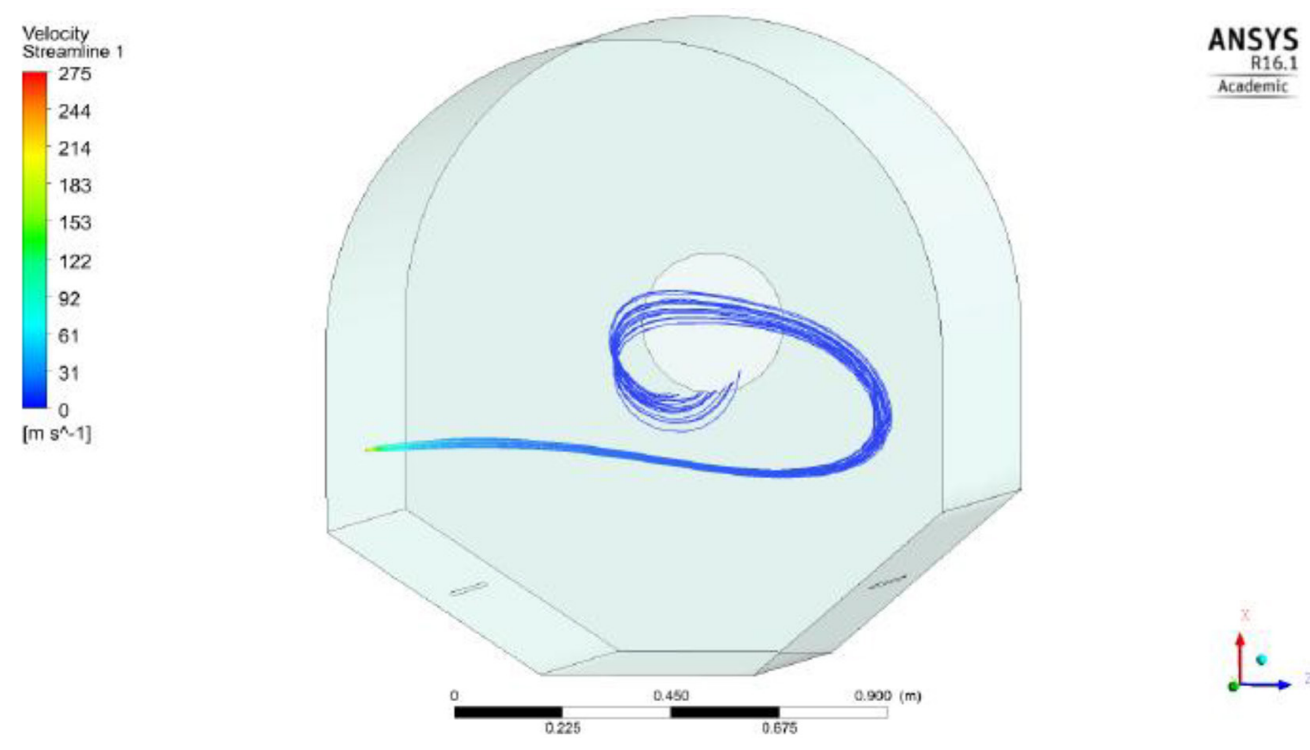

214

53

22

$\left.s^{\wedge}-1\right]$

Рис. 5. Траектории частиц топлива

Fig. 5. Trajectories of fuel particles

На рис. 5 изображены траектории частиц топлива. Анализ траекторий частиц показывает, что полученные траектории имеют форму спиралей. При этом выявлено, что время нахождения горящих частиц и капель ВУТ в вихревой топке пропорционально их диаметру, что позволяет обеспечить их эффективное выгорание.

Таким образом, организация сжигания ВУТ в вихревой топке позволяет обеспечить повышенное время удержания горящих частиц топлива в топочном пространстве, при этом в топочном объеме образуются локальные вихревые потоки. Оптимальный уровень температур составляет $800-1250{ }^{\circ} \mathrm{C}$ (рис. 6). 


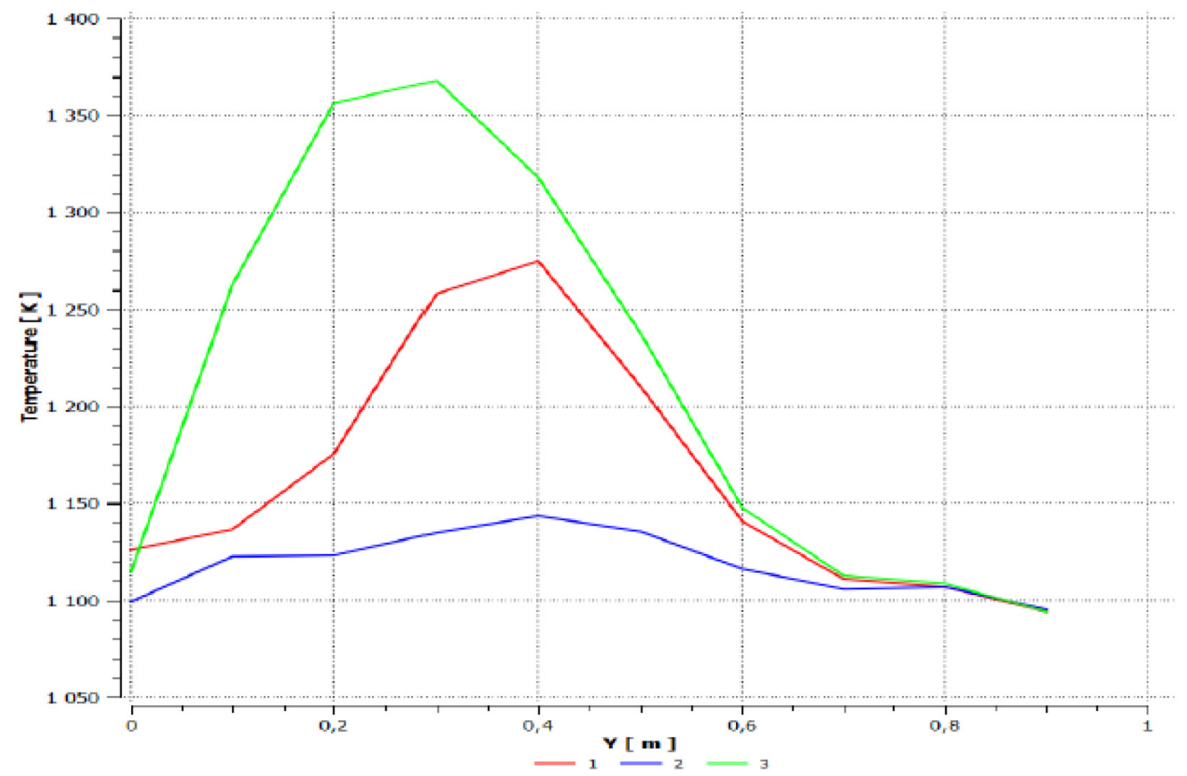

Рис. 6. Распределение температуры по глубине топки на различной высоте

Fig. 6. Temperature distribution over the depth of the furnace at different heights
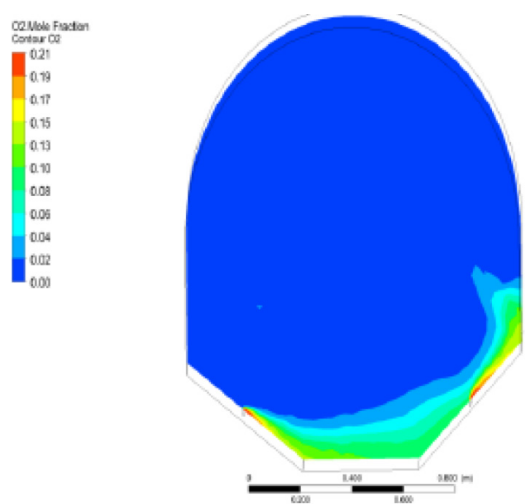

Рис. 7. Концентрация $\mathrm{O}_{2}$ в сечении горелки

Fig. 7. $\mathrm{O}_{2}$ concentration in the burner section
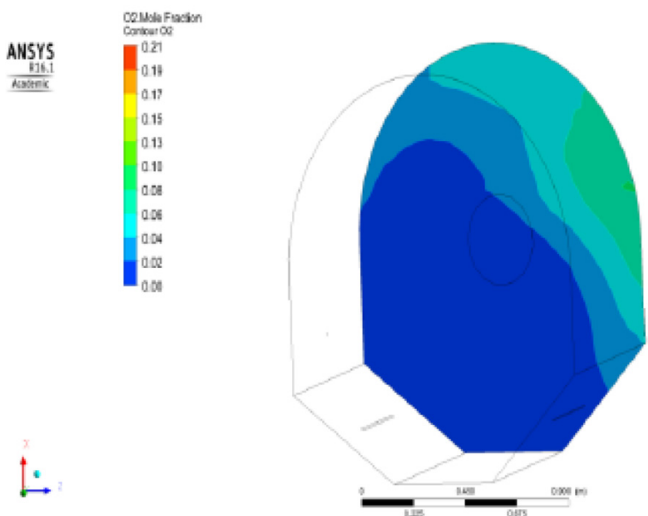

$\underset{\text { ANSYS }}{\text { Nhis }}$

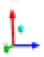

Рис. 8. Концентрация $\mathrm{O}_{2}$ у задней стенки топки

Fig. 8. $\mathrm{O}_{2}$ concentration at the back furnace wall

На рис. 7-10 представлены результаты расчетов концентрации кислорода $\mathrm{O}_{2}$ и диоксида углерода $\mathrm{CO}_{2}$ в направлении к задней стенке топки.

Анализ результатов (рис. 7-10) показывает, что к выходу топки наблюдается снижение концентрации $\mathrm{O}_{2}$ и увеличение концентрации $\mathrm{CO}_{2}$. Содержание летучих веществ также уменьшается.

\section{Заключение}

В результате выполненного анализа установлено влияние зольности водоугольного топлива на выход горючих газов и содержание водяного пара в атмосфере топки. На основании срав- 


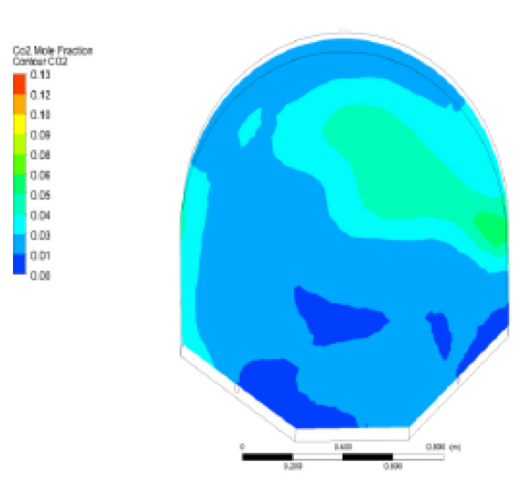

Рис. 9. Концентрация $\mathrm{CO}_{2}$ в сечении горелки

Fig. 9. $\mathrm{CO}_{2}$ concentration in the burner section
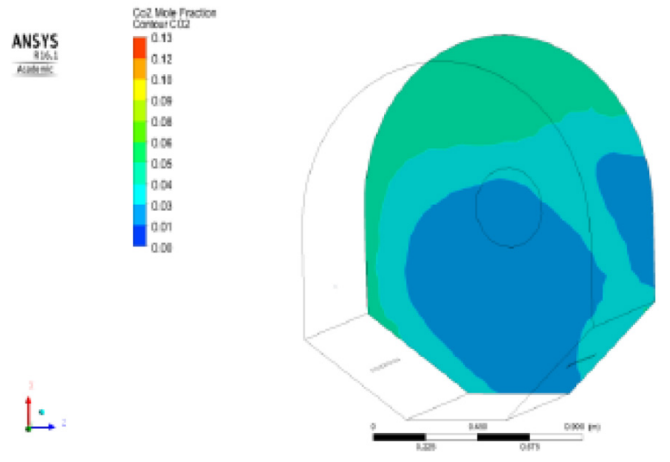

ANSYS

Рис. 10. Концентрация $\mathrm{CO}_{2}$ у задней стенки топки

Fig. 10. $\mathrm{CO}_{2}$ concentration at the back furnace wall

нения коэффициентов диффузии газов и рассчитанных значений констант равновесия реакции в зоне горения сделан вывод о ведущей роли реакции окисления углерода водяным паром в вихревой адиабатической топке.

Выполненные численные расчеты демонстрируют, что процесс горения указанных неоднородных систем: капель и чисто угольных частиц в адиабатической топке в течение короткого времени становится идентичным. При этом установлены концентрации кислорода $\left(\mathrm{O}_{2}\right)$, диоксида углерода $\left(\mathrm{CO}_{2}\right)$ и летучих веществ в различных сечениях топки. Выполненный анализ и численное моделирование процесса сжигания тонкодисперсных водоугольных суспензий в вихревой камере сжигания позволили иметь полную картину газодинамических и тепловых процессов в топочном объеме. Полученные данные свидетельствуют о работоспособности и высокой эффективности использования адиабатической вихревой топки для сжигания ВУТ в котлах малой и средней мощности.

\section{Благодарности / Acknowledgments}

Исследование выполнено при финансовой поддержке РФФИ в рамках научного проекта № 20-43-420016/20.

The study was carried out with the financial support of the Russian Foundation for Basic Research in the framework of scientific project No. 20-43-420016/20.

\section{Список литературы / References}

[1] Murko V. I., Karpenok V. I., Fedyaev V. I., Puzyryov E. M., Baranova M. P. The usage of boilers with a vortex furnace for burning enrichment products and deballasting coal. XVIII International Coal Preparation Congress. Conference proceedings. 2016, 345-350.

[2] Пузырев Е. М., Мурко В.И. и др. Результаты опытно-промышленных испытаний работы котла ДКВР 6,5/13 на водоугольном топливе. Теплоэнергетика, 2001, 2, 69. [Puzyrev E. M., Murko V. I. et al. Results of experimental-industrial tests of the DKVR6,5/13 boiler on water-coal fuel. Heat Power Engineering, 2001, 2, 69 (in Russian)]

[3] Мурко В.И., Федяев В.И., Карпенок В.И., Мастихина В.П., Айнетдинов Х.Л., Яковенко А.В., Бугров В.А., Воскобойников П.С. Разработка и создание технологического ком- 
плекса по сжиганию тонкодисперсных отходов углеобогащения в котельной ОАО «Междуречье». Уголь Кузбасса, 2010, 4, 102. [Murko V.I., Fedyaev V.I., Karpenok V.I., Mastikhina V.P., Ainetdinov H.L., Yakovenko A. V., Bugrov V. A., Voskoboinikov P.S. Development and creation of technological complex for combustion of fine-dispersed waste of coal preparation in the boiler unit of «Mezhdurechye» JSC. Coal of Kuzbass, 2010, 4, 102 (in Russian)]

[4] Мурко В.И., Федяев В.И., Прошунин Ю.Е., Почечуев А.А., Карпенок В.И., Хямяляйнен В. А. Результаты сжигания суспензионного водоугольного топлива в котле типа «Теплотрон». Журнал Сибирского федерального университета. Техника и технологии, 2018, 11(5), 560-566. [Murko V.I., Fedyaev V. I., Proshunin Y.E., Pochechuev I. A., Karpenok V. I., Khyamyalyainen V. A. The Combustion Results of Suspension Water Coal Fuel in the «Teplotron» Type Boiler. Journal of Siberian Federal University. Engineering \& Technologies, 2018, 11(5), 560-566 (in Russian)]

[5] Мурко В.И., Федяев В.И., Карпенок В.И., Шаньшин А.Е., Мухтаров А.Т. О возможности использования тонкодисперсных отходов углеобогащения ОФ «Энергетическая» в качестве основы для котельного топлива. Журнал Сибирского федерального университета. Техника и технологии, 2020, 13(6), 657-669. [Murko V.I., Fedyaev V.I., Karpenok V.I., Shanshin A.E., Mukhtarov A. T. On the Possibility of Using Fine Coal Waste of the Processing Plant «Energeticheskaya» as a Basis for Boiler Fuel. Journal of Siberian Federal University. Engineering \& Technologies, 2020, 13(6), 657-669 (in Russian)]

[6] Баноидзе П.А., Белых Б.Н., Власов Е.Л. и др. Перевод жидкотопливных отопительных котельных на сжигание водоугольного топлива. Энергетик, 1997, 2, 14-16. [Banoidze P.А., Belykh B. N., Vlasov E. L. et al. Transfer of liquid fuel heating boilers to the combustion of water-coal fuel. Energetic, 1997, 2, 14-16 (in Russian)]

[7] Мурко В.И., Федяев В.И., Хямяляйнен В.А. Физико-технические основы водоугольного топлива. Кемерово: Кузбассвузиздат, 2009, 195 с. [Murko V. I., Fedyaev V. I., Hämäläinen V. A. Physical and technical foundations of coal-water fuel. Kemerovo: Kuzbassvuzizdat, 2009, 195 p. (in Russian)]

[8] Сенчурова Ю.А. Совершенствование технологии сжигания водоугольного топлива в вихревых топках, автореф. дис. ... канд. техн. наук. Кемерово, 2008, 20 с. [Senchurova Yu. A. Improvement of the technology of combustion of coal-water fuel in vortex furnaces, abstract of dis. for the degree of Cand. tech. sciences. Kemerovo, 2008, 20 p. (in Russian)]

[9] Murko V.I., Fedyaev V.I., Karpenok V.I., Zasypkin I.M., Senchurova Yu.A., Riesterer A. Investigation of the spraying mechanism and combustion of the suspended coal fuel. Thermal Science, 2015, 19 / 1.243-251.

[10] Pinchuk V., Sharabura T.A., Moumane M., Kuzmin A. Experimental investigation of the influence of temperature, coal metamorphic stage, and of the size of coal-water fuel drop on the fuel drop combustion process. Inter. J. Energy Clean Environ, 2019, 20, 43-62.

[11] Григорьева И.С., Мейлихова Е.3. Физические величины: Справочник. М., Энергоатомиздат, 1991, 1232 с. [Grigorieva I. S., Meilikhova E.Z. Physical quantities: Reference book. M., Energoatomizdat, 1991, 1232 p. (in Russian)]

[12] Крестовников А.Н., Вигдорович В.Н. Химическая термодинамика, изд-е 2. М.: Металлургия, 1973, 566 c. [Krestovnikov A.N., Vigdorovich V.N. Chemical thermodynamics. 2nd ed., M., Metallurgy, 1973, 566 p. (in Russian)]

$$
-397-
$$


[13] Мурко В.И., Риестерер А., Цецорина С.А., Федяев В.И., Карпенок В.И. Результаты численного моделирования процесса сжигания водоугольного топлива. Ползуновский Вестник, 2011, 2/1, 230-234. [Murko V. I., Riesterer A., Tsetsorina S. A., Fedyaev V. I., Karpenok V. I. Results of numerical modeling of the process of combustion of water-coal fuel. Polzunovskiy Vestnik, 2011, 2/1, 230-234 (in Russian)]

[14] Мурко В.И., Карпенок В.И., Сенчурова Ю.А. Моделирование процесса распыления и сжигания тонкодисперсных водоугольных суспензий. Горение топлива: теория, эксперимент, приложения: тез. докл. ІХ Всерос. конф. с междунар. участием, Новосибирск, 2015, 99. [Murko V. I., Karpenok V.I., Senchurova Yu. A. Simulation of the process of spraying and combustion of finely dispersed coal-water suspensions. Combustion of fuel: theory, experiment, applications: report at IX All-Russia. conf. with int. participation, Novosibirsk, 2015, 99 (in Russian)] 